\title{
Macro-nutrientes no lençol freático em Floresta Intacta, Floresta de Manejo e Pastagem no norte de Mato Grosso
}

\author{
Nara Luisa Reis de ANDRADE ${ }^{*}$, Luciana SANCHES ${ }^{2}$, Osvaldo Borges PINTO JÚNIOR ${ }^{2}$, Carlos Alberto \\ Antunes DIAS², José de Souza NOGUEIRA²
}

\begin{abstract}
RESUMO
A remoção de uma cobertura florestal e sua substituição por outras formas de uso do solo tem sido uma constante no norte do estado de Mato Grosso podendo alterar os ciclos hidrológicos e biogeoquímicos dos ecossistemas. Neste contexto, o presente trabalho visou identificar a variação do fósforo e nitrogênio das águas do lençol freático em áreas de Floresta de Transição madura e intacta (Floresta Intacta), Floresta de Transição Manejada (Floresta Manejada) e Pastagem localizadas no norte de Mato Grosso. Foram realizadas mensalmente medidas do nível do lençol freático, de coletas de amostras de água para análises físico-químicas e mediçôes de precipitação e temperatura do ar, no período de janeiro/2005 a novembro/2006. Verificou-se uma sazonalidade na precipitação e na temperatura do ar. No período de estiagem as águas do lençol freático apresentaram maiores teores de nitrogênio e de fósforo total nas três áreas em estudo. Os maiores valores de nitrogênio e fósforo foram detectados nos ecossistemas florestais (Florestas Intacta e Manejada) como indicativo da função da cobertura vegetal na ciclagem dos nutrientes.
\end{abstract}

PALAVRAS-CHAVE: Floresta tropical, Macronutrientes, Águas subterrâneas.

\section{Macro-nutrients in the water sheet in Mature Forest, Management Forest and Pasture in the north of Mato Grosso}

\section{ABSTRACT}

Forest removal for other land uses has been a constant in the north of Mato Grosso and can alter the hydrological and biochemical cycles. In this context, the present work aims to identify the variation of phosphorus and nitrogen in the water sheet in areas of Mature Forest, Management Forest and Pasture in the north of Mato Grosso. The water level was measured monthly and water samples for analysis were collected monthly from January/2005 to November/2006. We verified the precipitation and the air temperature seasonality, and in the dry season the quality of the water sheet presented greater values of total phosphorus and total Kjeldhal nitrogen in the studied areas. The phosphorus and nitrogen presented greater values in forest ecosystems (Forest and Management Forest) as indicative of the function of the vegetal covering in the nutrient cycle.

KEYWORDS: Tropical Forest, Nutrients, Underground waters.

\footnotetext{
1 Programa de Pós-Graduação em Física Ambiental, Universidade Federal de Mato Grosso, Mato Grosso, Brasil.

2 Departamento de Engenharia Sanitária e Ambiental, Universidade Federal de Mato Grosso, Mato Grosso, Brasil.

* Correspondência: Programa de Pós-Graduação em Física Ambiental. Universidade Federal de Mato Grosso. Av. Fernando Corrêa da Costa, s/n. CEP 78960-900, Brasil. Telefone (+55) 653615 8748. E-mail: naraluisar@gmail.com
} 


\section{INTRODUÇÃO}

Em um ecossistema florestal, a água de precipitação que chega ao solo pode escoar superficialmente, ser assimilada pelas raízes da vegetação e infiltrar-se. Parte desta água que penetra no solo retorna à atmosfera pelo processo de evapotranspiração, permanecendo uma parcela armazenada no subsolo ou acumulada no lençol freático, dando origem a nascentes de pequenos rios e suprindo a necessidade hídrica dos ecossistemas locais. No solo, o conjunto dos íons inorgânicos e orgânicos na água é importante não apenas como fonte de águas e nutrientes para as raízes das plantas. $\mathrm{O}$ solo, formado por várias camadas, e a matéria orgânica desempenha papel fundamental na ciclagem de nutrientes dentro deste ecossistema. Quando um ecossistema natural é destruído ou alterado ele interrompe os ciclos hidrológicos e biogeoquímicos que funcionam em interação mantendo o equilíbrio entre as espécies e o meio.

Conhecer os elementos e a dinâmica de funcionamento de um ecossistema florestal intacto permite o desenvolvimento sustentável com um plano de ações que minimizem os impactos ambientais. O norte de Mato Grosso é parte da Amazônia Legal, área em que vem ocorrendo intensas substituições da vegetação nativa por pastagens ou monoculturas.

Neste contexto, o presente estudo teve como objetivo (a) analisar a variabilidade do nível de água do lençol freático em função da precipitação local, (b) avaliar as concentraçōes de fósforo e nitrogênio no lençol freático sob áreas de Floresta Intacta, Floresta Manejada e Pastagem buscando identificar a influência da cobertura do solo nas concentrações de nutrientes essenciais.

\section{MATERIAL E MÉTODOS}

\section{ÁREA DE ESTUDOS}

O presente estudo foi conduzido a aproximadamente 60 km NE da cidade de Sinop, Mato Grosso, Brasil, localizada em área de transição Amazônia - Cerrado, caracterizada por estaçôes de estiagem (maio a setembro) e úmida (outubro a abril).

As medições do nível da água do lençol freático e coletas de amostras para análise foram conduzidas em áreas de Floresta de Transição madura e intacta e Floresta Manejada, com uma copa fechada entre 28 - $30 \mathrm{~m}$ de altura, e área de Pastagem, de janeiro de 2005 a novembro de 2006. A Tabela 1 apresenta as características dos poços de monitoramento.

\section{MEDIDAS DE PRECIPITAÇÃO E TEMPERATURA}

A temperatura do ar foi medida por um psicrômetro (HMP-35, Vaisala, Inc., Helsinki, Finland) instalado a $41 \mathrm{~m}$ de altura em uma torre micrometeorológica pertencente ao Experimento de Grande Escala da Biosfera - Atmosfera na

\begin{tabular}{|c|c|c|c|c|}
\hline Descrição & $\begin{array}{l}\text { Tipo de } \\
\text { vegetação } \\
\text { original }\end{array}$ & $\begin{array}{l}\text { Tipo de } \\
\text { vegetação } \\
\text { atual }\end{array}$ & $\begin{array}{l}\text { Coordenadas } \\
\text { geográficas }\end{array}$ & Profundidade (m) \\
\hline $\mathrm{F} 1$ & $\begin{array}{l}\text { Floresta de } \\
\text { Transiçã̃o }\end{array}$ & $\begin{array}{l}\text { Floresta } \\
\text { Intacta }\end{array}$ & $55^{\circ} 19^{\prime} 0,11^{\circ} 24^{\prime} S$ & 6,00 \\
\hline F2 & $\begin{array}{l}\text { Floresta de } \\
\text { Transição }\end{array}$ & $\begin{array}{l}\text { Floresta } \\
\text { Intacta }\end{array}$ & $55^{\circ} 19^{\prime} 0,11^{\circ} 24^{\prime} S$ & 3,42 \\
\hline F3 & $\begin{array}{l}\text { Floresta de } \\
\text { Transição }\end{array}$ & $\begin{array}{l}\text { Floresta } \\
\text { Intacta }\end{array}$ & $55^{\circ} 19^{\prime} 0,11^{\circ} 14^{\prime} \mathrm{S}$ & 3,69 \\
\hline M1 & $\begin{array}{l}\text { Floresta de } \\
\text { Transiçã̃o }\end{array}$ & $\begin{array}{l}\text { Floresta } \\
\text { Manejada }\end{array}$ & $55^{\circ} 10^{\prime} 0,11^{\circ} 39^{\prime} S$ & 6,55 \\
\hline M2 & $\begin{array}{l}\text { Floresta de } \\
\text { Transição }\end{array}$ & $\begin{array}{l}\text { Floresta } \\
\text { Manejada }\end{array}$ & $55^{\circ} 10^{\prime} 0,11^{\circ} 39^{\prime} S$ & 3,35 \\
\hline P1 & $\begin{array}{l}\text { Floresta de } \\
\text { Transição }\end{array}$ & Pastagem & $55^{\circ} 21^{\prime} 0,11^{\circ} 25^{\prime} \mathrm{S}$ & 8,10 \\
\hline P2 & $\begin{array}{l}\text { Floresta de } \\
\text { Transição }\end{array}$ & Pastagem & $55^{\circ} 21^{\prime} 0,11^{\circ} 26^{\prime} \mathrm{S}$ & 2,16 \\
\hline P3 & $\begin{array}{l}\text { Floresta de } \\
\text { Transição }\end{array}$ & Pastagem & $55^{\circ} 21^{\prime} 0,11^{\circ} 26^{\prime} S$ & 4,15 \\
\hline
\end{tabular}

Amazônia (LBA) localizada na área de estudos $\left(11^{\circ} 24,75^{\prime}\right.$ S: $\left.55^{\circ} 19,50^{\prime} \mathrm{O}\right)$. Os dados foram coletados por um sistema data logger com freqüência de $30 \mathrm{~min}$ (Campbell CR10X - Campbell Scientific). Devido a problemas técnicos com o pluviômetro instalado na torre micrometeorológica na área experimental, optou-se por utilizar os dados de precipitação da estação meteorológica da Fazenda Continental, localizada à aproximadamente $17 \mathrm{~km}$ do local do experimento, que utiliza um pluviômetro fixável (Modelo 260-2530, NovaLynx Corporation, USA), instalado em área de manejo florestal, com medições diárias.

\section{MONITORAMENTO DO NÍVEL DA ÁGUA}

Nos oito poços de monitoramento foram realizadas medidas mensais do nível do topo de água do lençol freático com o uso de um medidor de nível. Foram calculadas médias mensais do nível do lençol freático em cada ecossistema. 


\section{DETERMINAÇÃO DA CONCENTRAÇÃO DE MACRO NUTRIENTES}

As coletas da água do lençol freático nos poços de monitoramento foram realizadas mensalmente por meio de uma bomba manual. $\mathrm{O}$ valor do $\mathrm{pH}$ foi determinado in situ por um medidor de $\mathrm{pH}$ digital, Check- Mite $\mathrm{pH}$ Sensor $(\mathrm{pH}-30) \mathrm{CE}$.

As amostras coletadas foram armazenadas em frascos de PVC e preservadas a temperatura de $4^{\circ} \mathrm{C}$ para posteriores análises em laboratório. Foram realizadas análises dos macronutrientes fósforo total e nitrogênio total, conforme métodos descritos no Standard Methods (APHA et al., 1998).

\section{RESULTADOS E DISCUSSÃO}

\section{VARIAÇÃO ANUAL DE PRECIPITAÇÃO, TEMPERATURA E DO TOPO DO NIVIEL DA ÁGUA}

A precipitação e temperatura do ar variaram sazonalmente durante $\mathrm{o}$ ano (Figura 1). A precipitação foi baixa de junho a agosto, apresentando um total $81 \mathrm{~mm}$ durante os meses secos (de maio a setembro), enquanto nos meses úmidos (de outubro a abril), o total foi $1931 \mathrm{~mm}$ (média anual 2012,5 mm), valor próximo ao encontrado por Villani et al. (2006), 2171 $\mathrm{mm}$, para a mesma área em estudos. $\mathrm{O}$ valor está dentro dos padrōes Amazônicos, onde, segundo Liebmann \& Marengo (2001) a média anual de precipitação na Amazônia Brasileira varia de $<2000 \mathrm{~mm}$ na parte sul a $>3000 \mathrm{~mm}$ na parte leste e extremo norte.

A temperatura média mensal apresentou maiores valores no mês de outubro $\left(29,0^{\circ} \mathrm{C}\right)$ e menores valores em dezembro $\left(26,0^{\circ} \mathrm{C}\right)$, com média anual de $28,0^{\circ} \mathrm{C}$. Estes valores foram maiores que os obtidos por Villani et al. (2006), em que a temperatura anual na floresta variou em $2,2^{\circ} \mathrm{C}$, de 25,6 a $27,8^{\circ} \mathrm{C}$, com uma temperatura média anual na floresta de transição de $26,4^{\circ} \mathrm{C}$ (anos 2001 a 2003). Foram também maiores do que a temperatura média na Floresta Tropical em Manaus e Marabá que apresentaram valores entre 24,5 e $26,6^{\circ} \mathrm{C}$ e em Ji-Paraná com temperaturas médias entre 22,1 e $25,7^{\circ} \mathrm{C}$ (Culf et al., 1996). Geralmente a temperatura e as condições da umidade dentro e acima de uma floresta são resultados da reflexão, da transmissão e absorção da energia solar na superfície do dossel, e da conversão da energia em calor sensível e latente e alocação da luz e calor dentro de uma floresta (Motzer, 2005).

O clima das regiōes da floresta tropical úmida exibe uma variação considerável nas temperatura, de acordo com Malhi et al. (2004) em que a média de precipitação da floresta tropical foi $2180 \mathrm{~mm}$, com uma estiagem de 3 a 4 meses, correspondendo a uma temperatura média anual de $25,2^{\circ} \mathrm{C}$ com uma variação sazonal de $3,2^{\circ} \mathrm{C}$.
Concordando com a precipitação e a temperatura do ar, o nível do lençol freático variou sazonalmente (Figura 2), apresentando médias na estação úmida (outubro a abril) de -2,9 m, -2,4 m e -2,6 m nas áreas de Floresta, Manejo e Pastagem, e, na estiagem (maio a setembro) de respectivamente $-3,7 \mathrm{~m},-2,4 \mathrm{~m}$ e - 3,3 m. Mínimos de -4,3 m (setembro), $-3,1 \mathrm{~m}$ (novembro) e - $3,9 \mathrm{~m}$ (agosto) e máximos de -2,6 $\mathrm{m}$ (fevereiro), -1,9 m (março) e -2,2 m (abril), foram verificados na Floresta, Manejo e Pastagem, respectivamente.

Não foi verificada uma resposta imediata na dinâmica do lençol freático em relação à precipitação em nenhuma das áreas, de modo que o nível do lençol freático atinge seu mínimo no fim do período seco a início das chuvas. Somente a partir de janeiro foi verificado uma resposta à precipitação (período de recarga).

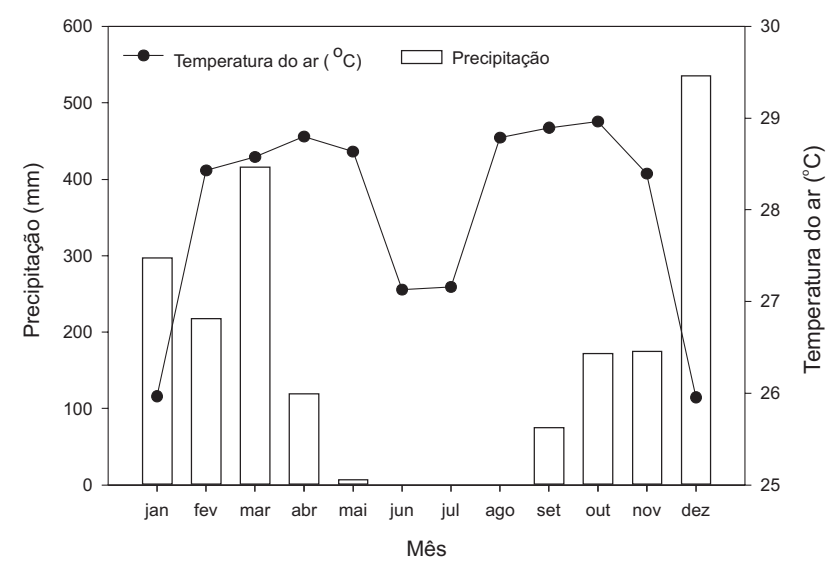

Figura 1 - Precipitação e temperatura do ar medidos em torre micrometeorológica localizada na floresta de transição Amazônia Cerrado.

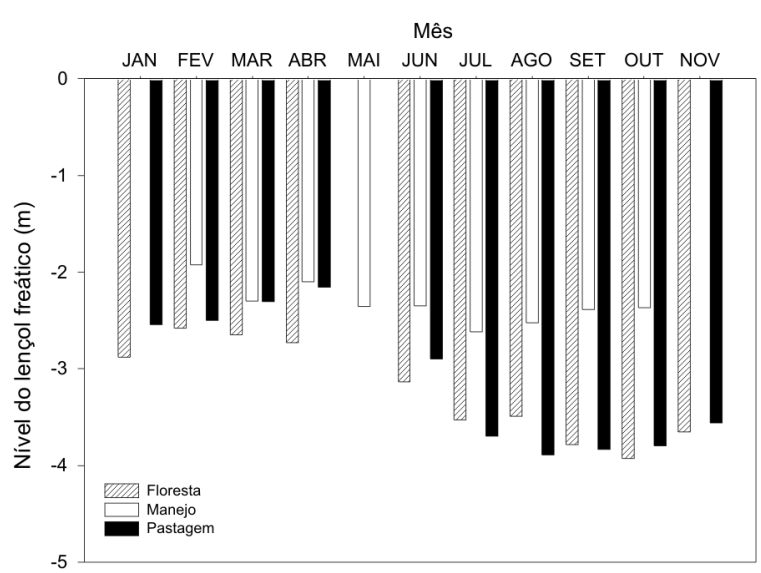

Figura 2 - Médias mensais do topo do nível da água (N.A) dos poços de monitoramento em áreas de Floresta Intacta, Floresta Manejada e Pastagem. 
A floresta intacta e a manejada possuem maior cobertura vegetal. Spolador et al. (2006) investigando a radiação fotossinteticamente ativa absorvida verificou que apenas $2,1 \%$ da radiação incidente no topo do dossel alcança o solo da floresta. Em uma área de pastagem a fração radiação fotossinteticamente ativa absorvida que alcança o solo é maior que na floresta, resultando neste ecossistema em maiores perdas por evapotranspiração. Os solos nos ecossistemas florestais possuem uma maior capacidade de armazenamento de água que uma área de pastagem que resulta em uma maior variação do nível do lençol freático (variação entre o mínimo e o máximo do nível) entre as estaçôes de seca e úmida.

As maiores precipitações e menores profundidades do nível do lençol freático foram verificadas na estação úmida nos ecossistemas de floresta (Tabela 2).

\section{TEORES DE MACRO NUTRIENTES NOS ECOSSISTEMAS}

A partir das análises laboratoriais mensais dos macro nutrientes fósforo total (P) e nitrogênio total Kjeldhal (NTK) foram calculadas médias sazonais (estaçōes seca e úmida) dos teores destes elementos referentes de cada poço (Figura $3 \mathrm{e}$ Figura 4).

Houve maior disponibilidade de fósforo nos poços F2 e F3, em ambas as estações. Para NTK, os maiores valores encontrados foram no M2 e F2, em ambas as áreas florestadas. Foram observados maiores valores médios de nitrogênio e fósforo na estação seca.

Os valores médios de fósforo e nitrogênio em todos os poços apresentaram comportamento sazonal com maiores valores na estação seca.

Os valores encontrados para teores de nitrogênio total nas estaçôes seca e úmida, para a Floresta, Manejo Florestal e Pastagem concordam com o comportamento do nutriente fósforo, de modo que, para ambos os nutrientes, foram observados maiores valores durante a estação seca. Menores concentrações deste nutriente foram observadas na Pastagem, em ambas as estaçōes (Tabela 3).

A relação nitrogênio:fósforo (N:P) para: Floresta, Manejo e Pastagem, foi de aproximadamente 4,5:1; 6:1; 7:1 na estação seca e 3:1, 14:1 e 3:1 na estação úmida.

Tabela 2 - Médias sazonais da precipitação, temperatura e nível do lençol freático dos poços de monitoramento nas estações seca e úmida.

\begin{tabular}{|c|c|c|c|c|c|}
\hline \multirow[b]{2}{*}{ Estação } & \multirow{2}{*}{$\begin{array}{l}\text { Precipitação } \\
(\mathrm{mm})\end{array}$} & \multirow{2}{*}{$\begin{array}{l}\text { Temperatura } \\
\text { do ar }\left({ }^{\circ} \mathrm{C}\right)\end{array}$} & \multicolumn{3}{|c|}{ Nível do lençol freático (m) } \\
\hline & & & $\begin{array}{l}\text { Floresta } \\
\text { Intacta }\end{array}$ & $\begin{array}{l}\text { Floresta } \\
\text { Manejada }\end{array}$ & Pastagem \\
\hline Úmida & 1931 & $\begin{array}{l}27,87 \pm \\
1,32\end{array}$ & $-2,9$ & $-2,2$ & $-2,6$ \\
\hline Seca & 81 & $\begin{array}{l}28,12 \pm \\
0,90\end{array}$ & $-3,6$ & $-2,4$ & $-3,6$ \\
\hline
\end{tabular}

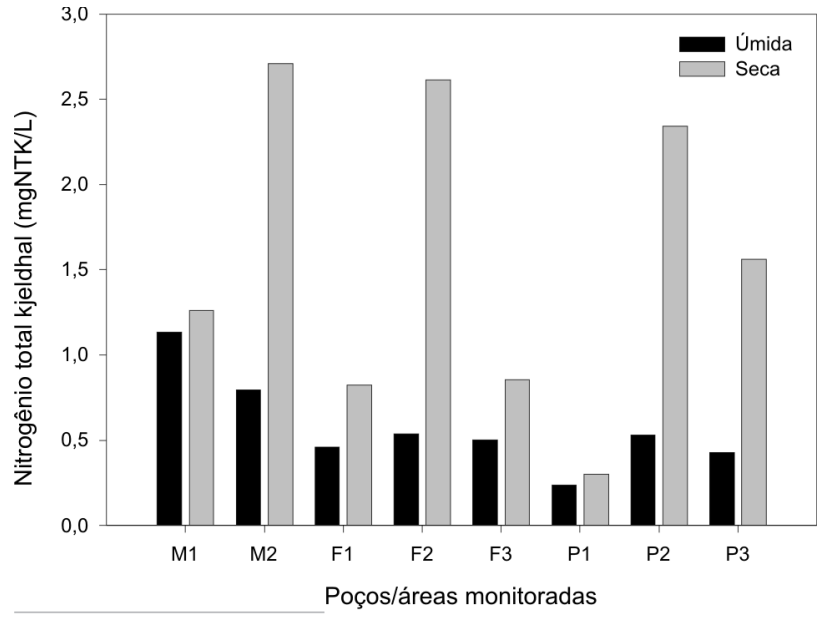

Figura 3 - Concentração de nitrogênio total Kjeldhal (NTK) nas águas do lençol freático nos poços na área em estudo nas estações úmida e seca.

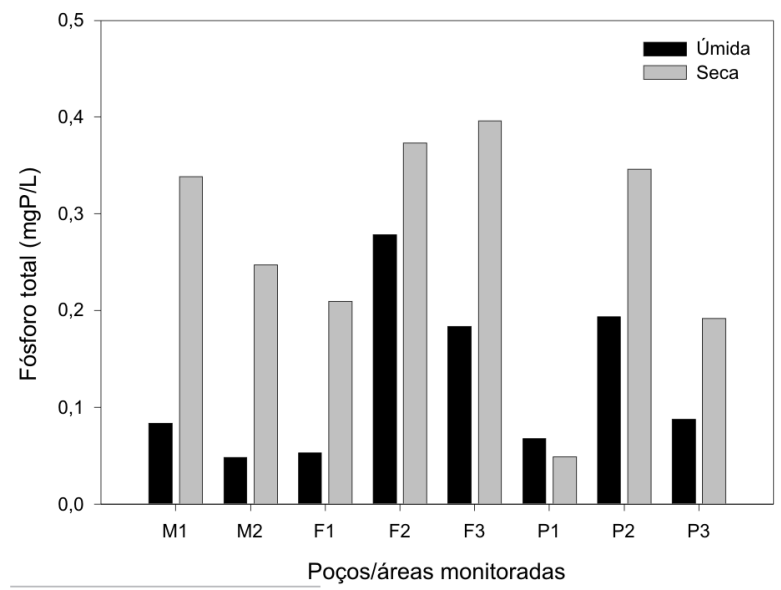

Figura 4 - Concentração de fósforo total $(\mathrm{P})$ nas águas do lençol freático nos poços de monitoramento na área em estudo nas (a) estação úmida e (b) estação seca.

O período de setembro a novembro é caracterizado pela transição entre a estação seca e a úmida. Com uma mudança característica nos ciclos de nutrientes dentro da floresta.

$\mathrm{Na}$ estiagem, ocorre um acúmulo de serrapilheira (material orgânico como folhas, galhos, flores, entre outros) no solo da floresta. Os maiores valores dos macro nutrientes (NTK, P) foram observados na estação seca (Tabela 3) para Floresta, Manejo e Pastagem, provavelmente porque os elementos móveis, como o nitrogênio, apresentam teores geralmente mais baixos na estação úmida, causado pelo maior crescimento da vegetação, com elevado consumo de nutrientes essenciais. Os valores médios para Floresta, Manejo e Pastagem na estação úmida foram de, respectivamente: $0,17 \mathrm{mg} \mathrm{L}^{-1}, 0,07 \mathrm{mg} \mathrm{L}^{-1} \mathrm{e}$ $0,12 \mathrm{mg} \mathrm{L}^{-1}$ (P) e $0,50,0,96$ e $0,40 \mathrm{mg} \mathrm{L}^{-1}$ (NTK) (Tabela 3). 
Tabela 3 - Médias sazonais do fósforo total e nitrogênio total nas águas do lençol freático nos poços de monitoramento nas estações seca e úmida.

\begin{tabular}{llllll}
\hline \multirow{2}{*}{ Nutriente } & \multirow{2}{*}{ Estação } & Área & & \\
\cline { 3 - 6 } & & Floresta Intacta & Floresta Manejada & Pastagem \\
\hline \multirow{2}{*}{ Fósforo Total $(\mathrm{mg} / \mathrm{L})$} & Seca & 0,32 & 0,30 & 0,19 \\
\hline \multirow{2}{*}{ Nitrogênio Total $(\mathrm{mg} / \mathrm{L})$} & Úmida & 0,17 & 0,07 & 0,12 & 1,40 \\
\hline
\end{tabular}

Os maiores teores de fósforo e nitrogênio encontrados na estação seca, condizem com estudos de Almeida et al. (2007) que investigaram o solo na floresta de transição no mesmo local do experimento do presente trabalho e verificaram um maior acúmulo de serrapilheira durante a estação seca e maiores percentuais de nutrientes do solo (Almeida et al., 2007). Também verificaram maiores teores de fósforo e nitrogênio durante a estação seca no solo da Floresta Intacta, a uma profundidade de $30-70 \mathrm{~cm}$, de $0,65 \mathrm{mg} \mathrm{kg}^{-1}$ e $0,55 \mathrm{mg} \mathrm{kg}^{-1}$, enquanto na estação úmida foram observados valores de 0,53 mg kg-1 de P e $0,39 \mathrm{mg} \mathrm{kg}^{-1}$ de NTK.

\section{CONCLUSÕES}

Registrou-se uma variação sazonal da precipitação e da temperatura do ar na região em estudo.

Registrou-se uma diferença no comportamento do lençol freático entre áreas florestadas manejadas e não manejadas (Floresta e Manejo) e Pastagem.

$\mathrm{Na}$ estação seca as águas do lençol freático apresentaram maiores teores de NTK e de P nas áreas em estudo.

\section{AGRADECIMENTOS}

Ao grupo de pesquisas da Pós-Graduação em Física e Meio Ambiente (PGFMA) da Universidade Federal de Mato Grosso (UFMT), por viabilizar a realização deste trabalho; à CAPES, pela concessão de bolsa PRODOC e ao CNPq pela concessão de bolsa PIBIC.

\section{BIBLIOGRAFIA CITADA}

Almeida, E.D.; Sanches, L.; Nogueira, J.S. 2007. Nitrogênio e fósforo no solo de uma floresta de transição Amazônia Cerrado. (Submetido).

American Public Health Association (APHA); American Water Works Association (AWWA); Water Environment Federation (WEF).1998. Standard methods for the examination of water and wastewater. 20. ed. APHA, Washington, USA.1085pp.

Culf, A.D., Esteves, J.L., Marques Filho, A.O., Ocha, H.R.1996. Radiation, temperature and humidity over forest and pasture in Amazonia. In: Gash, J.H.C.; Nobre, C.A.; Roberts, J.M (Eds). Amazonian Deforestation and Climate. J.M. Wiley and Sons, New York. p. 175-191.

Liebmann, B.; Marengo, J.A. 2001. Interannual variability of the rainy season and rainfall in the Brazilian Amazon Basin. J. Climate, 14:4308-4318.

Lopes, A.S. 1989. Manual de Fertilidade do Solo. ANDA/POTAFOS, São Paulo. 153pp.

Malhi, Y.; Wright, J. 2004. Spatial patterns and recent trends in the climate of tropical rainforest regions. The Royal Society, 359:311-329.

Motzer, T. 2005. Micrometeorological aspect of a tropical mountain forest. Agricultural and Forest Meteorology, 135:230-240.

Spolador, J.; Sanches, L.; Costa, M.H. 2006. Radiação fotossinteticamente ativa em uma floresta de transição CerradoAmazônica. Revista Brasileira de Meteorologia, 21:89-95.

Vilani, M.T.; Sanches, L.; Nogueira, J.S.; Priante Filho, N. 2006. Sazonalidade da radiação, temperatura e umidade em uma floresta de transição Amazônia Cerrado. Revista Brasileira de Meteorologia, 21:119-131.

Recebido em 12/06/2007

Aceito em 02/05/2008 
